\title{
Engaging Foreign Curriculum Experts in Curriculum Design: A Case Study of Primary School Curriculum Change in Lesotho
}

\author{
Molise David Nhlapo*, Lokesh Ramnath Maharajh \\ School of Education, Edgewood Campus, University of KwaZulu-Natal, South Africa
}

Copyright $\mathrm{O} 2017$ by authors, all rights reserved. Authors agree that this article remains permanently open access under the terms of the Creative Commons Attribution License 4.0 International License

\begin{abstract}
Involvement of foreign consultants in the Lesotho curriculum design has been in operation since the beginning of formal education around 1833 in the country to-date. The expectation was that, with time, Lesotho would produce enough quality curriculum specialists who would be entrusted with the task of curriculum design. However, the trained citizens continued to engage foreign consultants in curriculum design. This paper presents some of the reasons for continued engagement of foreign consultants in the Lesotho curriculum centre. The study is a case study in which a qualitative approach was used as the conceptual framework to interrogate the value of curriculum specialists mandated to design the Lesotho curriculum. Data used in this study were solicited from one-on-one interviews of curriculum specialists. The findings reveal one of the main reasons for engaging foreign consultants as lack of training for newly employed curriculum specialists while on the other hand, less qualified and inexperienced curriculum specialists are employed which led to a huge staff turnover due to unfavourable working conditions in the Lesotho curriculum development centre. This resulted in the lack of knowledge of curriculum design where curriculum specialists took too long to design a low quality curriculum.
\end{abstract}

Keywords Quality, Foreign Consultant, Curriculum Design, Fitness for Purpose, Epistemological Access

\section{Introduction}

Curriculum design and development is one of the initial processes in teaching and learning since it informs what should be taught and learnt in schools. In curriculum design, a country's educational policies, goals, mission and vision are interpreted and transformed into general objectives, which can be easily transferred by school teachers into instructional objectives and learning standards.

\subsection{The Nature of Curriculum}

One of the properties of curriculum is that it is not stagnant but changes frequently to cater for modernization. However, curriculum design and curriculum change are among the most expensive processes in any education system. Some of the expenses emanate from production of instructional materials, training of teachers and curriculum developers and stakeholders. In most cases, curriculum change and design involves the engagement of foreign curriculum experts. An example of such is the South African Curriculum 2005 (C2005), which was accompanied by a strategy called Outcomes-based Education. OBE was imported from the USA and New Zealand by the new government of the ANC to phase out the Apartheid type of education. As observed by Reference [1], the goal of Outcomes-based Education (OBE) in South Africa was to move away from the Apartheid curriculum and to promote important problem-solving and critical-thinking skills the country needed. OBE focused on learner-centred, self-discovery learning and de-emphasised content. However, the implementation of OBE proved to be problematic because it requires well-trained teachers, small class sizes and resources. The problems observed in the C2005 of South Africa, as argued by Jansen [2], could also be attributed to the use of foreign curriculum experts without paying attention to the local context which Reference [3] refers to as the stage of ownership, internal initiative, internalisation or appropriations. As much as it is an example of a change influenced by politics, the $\mathrm{C} 2005$ of South Africa is also an example of a change of curriculum to organise subjects in the form of integration as a number of countries including Lesotho and Jamaica have adopted. This type of curriculum orientation which Reference [4] refers to as interdisciplinary concepts where topics are placed under one theme, is not well known by local teachers and curriculum experts. 


\subsection{Foreign Curriculum Experts' History in Lesotho}

This lack of expertise usually calls for foreign curriculum experts to be engaged. In Lesotho, there has been a series of foreign curriculum experts that have assisted the country in curriculum design and development. Table 1 below shows some of the foreign curriculum experts who have been assisting Lesotho in curriculum design and development.

\subsection{Situating Lesotho}

Lesotho is a small mountainous country that is landlocked by South Africa and has a population of roughly two million. According to [Reference 28], "the country has a low primary school completion, at only 64 percent in 2014 . The adult literacy rate in Lesotho of 76 percent in 2009 was below the national rate of 86 percent in 2000 but above the sub-Saharan Africa average of 60 percent in 2010." [Reference 29] reports that the introduction of Free Primary Education (FPE) in 2000, starting with Grade 1, resulted in a dramatic rise in intake and overall enrolment, which increased from 364,951 in 1999 to 410,745 in 2000; a rise of 12.5 percent. Since the paper focuses on primary education, it is also worth mentioning that, of this enrolment, there were 214746 boys and 214974 girls. Lastly, Lesotho is a country with the third lowest English-reading performance and the fourth lowest math performance [reference 28].

\section{Materials and Methods}

\subsection{Research Design}

This paper reports on a qualitative case study research of one curriculum institution in Lesotho in which one-on-one interviews were conducted to collect rich in-depth data from curriculum specialists.

\subsection{Research Type}

The methods of data collection in qualitative design favour mostly interviews whereby there is much text collected in the form of words (Reference [5, 6]). In this study curriculum developers were encouraged to participate and interact fully where the interviewer probed for clarity of specific aspects relating to Lesotho curriculum design and stimulated participants to give full answers (Reference $[7,8]$ ). The interviews allowed for in-depth information from the curriculum developers (Reference [9]). In other words, the interviews produced very detailed and descriptive information collected in the form of words (Reference [10]). The detailed transcripts of interviews produced permitted the researcher to identify themes (Reference $[11,12]$ ). Interviews allowed the researcher to enter into curriculum developers' perspectives and as a result, the researcher was in a position to understand and portray their perceptions and understanding of curriculum design in Lesotho (Reference [13]). Interviews may be structured, unstructured or semi-structured (Reference [14]). In the case of structured interviews, specific questions and the order in which they are asked are determined prior to the interview process, whereas unstructured interviews explore the topic areas without specific questions or a pre-determined order (Reference [15]). This research utilised the semi-structured interviews whereby an interview schedule was developed prior to the interview but the interviewer probed for insufficiently answered questions.

Table 1. History of foreign curriculum experts in Lesotho

\begin{tabular}{|c|c|c|}
\hline Date & Reform & Foreign curriculum experts \\
\hline 1967 & Implementation of UNICEF Primary school syllabus; & Tutors from University of Durham Institute of Education (UK) \\
\hline 1974 & Supervision of review of curriculum materials & British Overseas Development Administration Adviser (UK) \\
\hline 1974 & Advise on a systematic design of curriculum for Lesotho & Hugh Hawes from London University (UK) \\
\hline 1978 & National dialogue to share experiences of curriculum design. & $\begin{array}{l}\text { Dr. Babs Fafunwa-Nigeria; Dr. Gilbert P. Olouch-Kenya; Dr. } \\
\text { Barnabas Otaala-Kenya }\end{array}$ \\
\hline 1998 & $\begin{array}{l}\text { To integrate Population and Family Life Education into school } \\
\text { syllabus }\end{array}$ & A consultant from Uganda \\
\hline 2001 & To integrate Environmental Education into school syllabus & $\begin{array}{l}\text { Chief Technical Adviser-Karl J. Stark. Teacher Trainers-Niels } \\
\text { Kerstein Knudsen and Else-Marie Thuesen. }\end{array}$ \\
\hline 2008 & Introduction of Life Skills Education subject. & Two life skills consultants from Malawi. \\
\hline 2011/12 & Development of curriculum packages for Grades 1-3. & Dr Simone Doctors (UK) \\
\hline 2012 & $\begin{array}{l}\text { Review and revision of Life skills and Sexuality Education } \\
\text { Curriculum. }\end{array}$ & Dr. Sheila Wamahiu-UN consultant based in Kenya \\
\hline 2013/14 & Development of curriculum packages for Grades 4-5. & Dr Simone Doctors (UK) \\
\hline
\end{tabular}




\subsection{Inclusion/Exclusion Criteria}

The focus of the study is on involvement of foreign consultants in primary school science curriculum design, but the challenge is, the engagement of consultants was not only for primary science but also for all subjects and projects. For this reason, the selection of participants was on science curriculum specialists and project coordinators. The curriculum specialists selected for this study were as follows:

Four members of the panels, who are responsible for the technical work in the development of primary curriculum, were interviewed. These consisted of a primary school science curriculum specialist, Life Skills education (LSE) curriculum specialist, one member of the panel who is not an employee of the Lesotho government but works as a lecturer in the National University of Lesotho; and the lead in-house contact person (Reference [16]) who was responsible for the selection of consultants and the drafting of terms of reference for at least three consultants recently engaged at the NCDC. Two directors (one former and one current) of curriculum development centre and CEO were selected to participate. Moreover, any number of available international consultants who had been engaged to help in the design and development of primary school science curriculum were selected to participate. One consultant focused on the Life Skills Education syllabus while the other assisted the development of the integrated primary curriculum of which science was one.

\subsection{Choice of Subjects}

There were four (4) curriculum specialists, two (2) directors and one (1) CEO selected as participants for the study as indicated in table 2 below.

\subsection{Methodology}

\subsubsection{Sample Collection}

There were seven (7) participants invited to participate but only five (5) volunteered to take part in this study. The profile of curriculum specialists who took part in the study is shown in table 3 below.

Data were collected from four curriculum specialists and one NCDC director. Interviews with the Director of NCDC were held in order to obtain information on the rationale for the involvement of foreign consultants in the curriculum design of Lesotho. Director-NCDC is responsible for the acquisition of services of foreign consultants once the need for a consultant has been identified. He then submits the requisition for approval to the Chief Education Officer for Curriculum and Assessment Services (CEO-CAS). There were plans to interview CEO-CAS, prior to and during the engagement of two consultants but she declined at the last minute despite having agreed to the interview and having seen the interview schedule.

Cognizant of the fact that qualitative research interviews are collaboratively produced between the interviewer and the interviewee (Silverman [17]), we held all the interviews in a place where the respondents would be free to talk without feeling intimidated. For curriculum specialists, interviews were held in their offices at the curriculum development centre (NCDC). As most of them occupy offices individually, these were quiet rooms with no disturbances from other offices. All the interview meetings were planned for the convenience of the officers and where there were two officers in one office, the interviews were held in a vacant separate room to avoid interruptions from the observer. Two of the interviews were held at workshop venues (Lake-Side Hotel) as the officers held residential dissemination workshops for the curriculum developed with the assistance of foreign consultants. The workshops were for the education officers and District Resource Teachers (DRTs) who, in turn, were supposed to cascade the information to schools' representatives and the schools' representatives to pass knowledge to teachers in schools. We attended workshops as per invitation of the participants (curriculum specialists and Director-NCDC) where I was assured that they would have spare time within their workshop schedule for interviews. These were also held in separate quiet rooms with no disturbances from the workshop attendees.

Table 2. Method of data production - interviews

\begin{tabular}{|c|c|c|l|}
\hline Participants & Frequency & Tool & Reasons \\
\hline $\begin{array}{c}\text { Curriculum } \\
\text { specialists }\end{array}$ & 3 & One-one interviews & $\begin{array}{l}\text { Rationale for foreign experts' engagement. Weaknesses of local experts and strengths of } \\
\text { foreign curriculum experts. }\end{array}$ \\
\hline $\begin{array}{c}\text { NCDC } \\
\text { Director }\end{array}$ & 2 & One-one interviews & Experiences of local and foreign curriculum experts. \\
\hline CEO-Cu & 1 & One-one interviews & Challenges of local experts and benefit of involving foreign curriculum experts. \\
\hline
\end{tabular}

Table 3. Participants' profile

\begin{tabular}{|c|c|c|c|}
\hline Participant & Occupation & Place & Curriculum experience \\
\hline Curriculum expert 1 & University lecturer & Withheld & Subject specialist, NCDC panel member. \\
\hline Curriculum expert 2 & Curriculum specialist & $\mathrm{NCDC}$ & Core subject specialist, panel chair \\
\hline Curriculum expert 3 & Education officer & Withheld & Subject specialist, project coordinator, panel chair. \\
\hline Curriculum expert 4 & Lead-in-house & NCDC & Subject specialist, project coordinator, panel chair. \\
\hline Director-NCDC & Curriculum manager & NCDC & NCDC director, subject specialist, panel chair. \\
\hline
\end{tabular}


The fact that data in this research is mainly collected through interviews might raise suspicion of quality and quantity. However, Gubrium and Holstein (2001) [reference 30] claim that we should not provide the practical basis for learning from strangers. In that case, the data for this research is collected from a relevant audience (not strangers), the primary school science curriculum specialists, who design and develop the curriculum on a daily basis. Interviews are regarded as one of the effective methods of data collection. [Reference 30, p.10] argues that "we all live in what might be called an interview society in which interviews seem central to making sense of our lives". They further claim that the confessional properties of interviews construct more and deepen and broaden the subjects' experiential truths. Stated differently, they describe the interview as "part and parcel of our society and culture ...... it is now an integral, constitutive feature of our everyday lives." Therefore, we chose this method for this research to solicit knowledge from the role players about rationale for involving foreign curriculum experts in local curriculum design.

\subsubsection{Data Processing}

Data in this research were collected mainly through interviews as stated above. In interviews, much text is collected in the form of words (Reference [5, 18]). For this research, we analysed the data generated through the interviews of curriculum specialists using content analysis. This qualitative approach to data analysis helped us to describe how NCDC curriculum specialists are developing a science curriculum with the assistance of curriculum consultants. "Reference [7] argues that content analysis takes texts and analyses, reduces and interrogates them into summary form through the use of both pre-existing categories and emergent themes in order to generate or test a theory."

To analyse data from curriculum specialists, we used features of the process of content analysis described by Reference [7]. The first feature is "breaking down text into units of analysis". This incorporates a number of steps we took to process data such as definition of research questions to determine the text to be analysed. In this case, we started by the identification of the type of population, from which units of texts are to be sampled, which are the interview transcripts of curriculum specialists. The curriculum specialists were categorised into three groups namely, subject specialists employed by NCDC to design the Lesotho curriculum; subject specialists who are members of the primary school science curriculum panel from stakeholder institutions but not employed by NCDC; and the authorities at NCDC in the form of directors and CEO-CS. These categories permitted us to identify the coding units from the text and context and we then decided on the codes to be used in the analysis in order to pull together a wealth of material into some order and structure. In this research, we have used "situation codes" that fall under descriptive codes depicting the perspectives held by curriculum specialists and ways of thinking about people and objects (Reference [7]). This descriptive and analytic data enabled us to identify patterns that could be used critically to interpret the rationale for engagement of foreign consultants in science curriculum documents' development.

The second feature we used is "undertaking statistical analysis of the units". This is where after looking for patterns, regularities and relationships between segments of the text, we employed statistical techniques to categorize text by calculating trends, frequencies, priorities and relationships. This was then followed by factor analysis to group the kinds of responses from curriculum specialists.

\section{Results}

Lesotho has always depended on donor assistance for the development of its education system due to factors such as political instability and escalating trade deficit [Reference 32]. Similarly, [Reference 33] argue that the Ministry of Education and Training is dependent on donor funding to achieve their intended goals. The major contributors that support the education sector in Lesotho are World Bank, GTZ and IRISH AID [Reference 34]. The curriculum change of 2009 to 2016 in Lesotho, on which this paper is based, was mainly funded by the World Bank. Therefore, the procedures followed to select consultants for this innovation were the World Bank procurement procedures.

The selection procedure used as per World Bank requirements is called the quality-cost based selection method. In this procedure, there are three aspects described by Reference [19] that guide selection of consultants. To qualify for the engagement of a consultant in World Bank projects, the candidate should have:

1. General qualifications,

2. Adequacy for assignment and

3. Experience in the region and language (Reference [19]).

We decided to utilize these criteria by the World Bank to evaluate the conformity to the quality and standard for World Bank projects by curriculum specialists mandated to design the curriculum of Lesotho. Table 4 below summarizes the findings from the interviews with curriculum specialists: 
Table 4. Findings of curriculum experts' interviews

\begin{tabular}{|c|l|}
\hline Criteria & \multicolumn{1}{c|}{ Curriculum specialists } \\
\hline $\begin{array}{c}\text { General qualification } \\
\text { Total duration of professional activity and level of education } \\
\text { and training }\end{array}$ & $\begin{array}{l}\text { There is none of the curriculum specialists with a PhD, a few have Masters } \\
\text { degrees, most of them have first degrees, and there is huge staff turnover and staff } \\
\text { retirement hence shortage of experienced staff. }\end{array}$ \\
\hline $\begin{array}{c}\text { Adequacy for assignment } \\
\begin{array}{c}\text { Education, training and experience in specific sector, field and } \\
\text { subject directly relevant to assignment }\end{array}\end{array}$ & $\begin{array}{l}\text { A few have Masters degrees in curriculum studies. Some have Masters degrees in } \\
\text { other fields such as Management. Most have never gone for any training in } \\
\text { curriculum. }\end{array}$ \\
\hline $\begin{array}{c}\text { Experience in the region and language } \\
\begin{array}{c}\text { Knowledge of national or local conditions, culture, } \\
\text { administrative systems and government organisations. Ability } \\
\text { to communicate in the national language. }\end{array}\end{array}$ & $\begin{array}{l}\text { All specialists know context, culture, local language and have taught in local } \\
\text { schools for the minimum of five years. }\end{array}$ \\
\hline
\end{tabular}

\subsection{General Qualification}

None of the curriculum specialists has a $\mathrm{PhD}$ level of study. The highest level of education and training for curriculum specialists are Masters' degrees as mentioned by one of the curriculum specialists thus: "The local consultants (curriculum experts) are at a low level; they only do masters in curriculum".

\subsection{Adequacy of Assignment}

At the level of Masters' degrees, some curriculum specialists have appropriate qualifications in curriculum while some have Masters' degrees in other fields different from curriculum. There are also curriculum specialists who do not have any training in curriculum.

\subsection{Experience}

We investigated the experience of participants in two categories. The first is professional activity and the second is knowledge of culture and local language.

\subsubsection{Professional activity}

Curriculum specialists do not involve themselves in curriculum-related activities both at the Curriculum Development Centre and in the world of education. Interviewees complain that curriculum specialists return from schools to be office bearers and are not involved in educational research. They do not interact with the outside world, they do not attend and present papers in conferences, and are not writing books and academic papers.

\subsubsection{Knowledge of culture and language}

It is important for a consultant to have cultural awareness and sensitivity of the area in which the assignment is taking place (Reference [20]) and fortunately, data shows that curriculum specialists know the context, culture of the country, understand and speak local language and have taught in local schools for the minimum of five years.

\section{Discussion}

\subsection{General Qualification}

Curriculum institutions, such as NCDC, should have access to the most qualified individuals in the field (Reference [21]). This is because general educational levels of staff and their specific preparation in education predict the richness of the curriculum (Reference [22]). In addition, curriculum specialists should be experts and intellectually productive academics (Reference [23]). To employ unqualified curriculum specialists and expect them to do quality work leads to certain failure (Reference [24]). In agreement with this argument, the American National Association for the Education of Young Children (NAEYC) provides the standards that early childhood educators should possess within childhood settings (Reference [27]). The analysis of these guidelines shows three main categories of knowledge for educators as content knowledge, pedagogical knowledge and language and culture.

\subsection{Adequacy for the Assignment}

"Reference [25] outlines the specifications required for the curriculum specialists as follows:

1. Master's Degree in Education plus a minimum of three (3) years' work experience as a Curriculum/Subject Specialist. Specialization in Curriculum Design and Development as well as assessment will be an added advantage.

OR

2. Bachelor's Degree in Education plus five (5) years as a Curriculum/Subject Specialist in Science."

As discussed earlier, adequacy for the assignment is the education and training in the specific field and subject directly relevant to the assignment (Reference [26]), curriculum specialists need to meet requirements specified above in the job advertisement to have adequacy for the assignment.

Data shows that some curriculum specialists do not have adequacy for the assignment of curriculum design and development. Curriculum specialist 4 admits NCDC employs curriculum specialists with no proper qualifications: "Some of them are still from teaching without any training in curriculum development. So the new curriculum specialists join the center (NCDC) straight from teaching, they are not even given the basics of curriculum development. Director-NCDC explains why some curriculum specialists 
do not have relevant qualifications: "...sometimes the candidate with experience but without qualifications is selected (employed) over the one with qualifications but lacks experience... These people have been involved with developing the curriculum for some years but their qualifications lack curriculum development modules."

Curriculum specialists do not meet the specifications since they have low levels of education and some do not have qualifications relevant to curriculum. It is not surprising that NCDC engages consultants to assist curriculum specialists to design curricula whenever there is curriculum innovation. This is because "educators who are qualified, well-resourced and supported are critical to program success" (Reference [22]), and the opposite is also true. The government of Lesotho cannot expect quality curriculum if it does not train curriculum specialists and employ appropriately qualified curriculum specialists. Therefore, if those appropriately qualified curriculum experts are found outside the borders of Lesotho, then for sake of the quality of education in Lesotho, the government of Lesotho has done a sensible thing to engage foreign curriculum experts. Besides, curriculum developments are not sealed airtight within national boundaries. "Just as economic, political, and ecological phenomena increasingly ignore national boundaries, so do educational issues" (Pinar, et al., 2014) [reference 31, p.793].

\section{Conclusions}

\subsection{Concluding Remarks}

In conclusion, the paper highlighted that the curriculum specialists mandated to design and develop the curriculum of Lesotho fall short on some specifications of World Bank for procurement of consultants. Firstly, regarding general qualifications, which refer to the level of education, most curriculum specialists do not have a high level of qualifications. Their qualifications range from first degrees to Masters' degrees and they are never encouraged to pursue a $\mathrm{PhD}$, since the Ministry of Education and Training does not offer study leave for anyone intending to further his/her studies beyond a PhD. Secondly, regarding the adequacy for assignment, curriculum specialists also do not conform to the specification. Adequacy for assignment refers to having appropriate qualifications for the position of the work one is doing. As curriculum specialists, they should be adequately qualified in the curriculum field. The paper discovers that some hold qualifications in curriculum studies but the majority either have Masters' degrees in other fields not specific to curriculum studies or they have no Masters' degrees. Those who have Masters' degrees majored in other fields such as management and leadership. The reason provided for having unqualified curriculum specialists is that there was hope that they will be trained as this used to be a norm. Again, the curriculum specialist is not an attractive job in Lesotho. There is a high turnover for curriculum specialists, leaving NCDC for other institutions such as the College of Education, the National University of Lesotho, Examinations Council of Lesotho and other government and UN agencies. In short, this means that there are curriculum specialists mandated to design and develop the curriculum of the country but with no training in curriculum matters.

Finally, regarding the experience of curriculum specialists, there are two categories. The first is the experience in the region and knowledge of culture and language, to which all local curriculum specialists conform since they are all citizens of Lesotho; they are familiar with culture, beliefs, context and language of Lesotho. The second one is professional activity which refers to engagement in curriculum activities nationally and internationally. The research reveals that curriculum specialists do not involve themselves in curriculum-related activities. The participants stated that there are no research studies conducted by curriculum specialists in Lesotho schools and therefore will write paper articles which will result in none attendance of educational symposiums. This means that they do not interact with the outside world since they do not attend and present papers in conferences, and they are not writing books and academic papers.

There is potential for future studies related to this research such as an investigation into other aspects that could have influenced selection of consultants to choose foreign consultants over local consultants. Another research could be a desktop study to compare curriculum documents designed and developed with assistance of foreign consultants and the one developed without foreign consultants' assistance. Lastly, a research which investigates the implementation of new curriculum in schools should be done to determine its success in schools.

\section{REFERENCES}

[1] G. Stols, Y. Ono, J. Rogan. What constitutes effective Mathematics teaching? Perceptions of teachers, African Journal of Research in Mathematics, Science and Technology Education, Vol. 19, No.3, 225-236, 2015.

[2] D. J. Jansen. Why Outcomes-based education will fail: An elaboration. In: D. J. Jansen \& P. Christie (Eds.). Changing curriculum: Studies on outcomes-based education in South Africa (pp. 145 - 156), Juta, Cape Town, 1999.

[3] C. A. Spreen. Appropriating borrowed policies: OutcomesBased Education in South Africa. In: G. Steiner-Khamsi (Ed.). The global politics of educational borrowing and lending (pp 101-113), Teachers College Press, New York, 2004.

[4] C. J. Marsh. Key concepts for understanding curriculum $\left(4^{\text {th }}\right.$ ed.), Routledge, New York, 2009.

[5] D. Festinger. Essentials of research design and methodology, John Wiley \& Sons, London, 2005.

[6] G. Marczyk, D. DeMatteo, D. Festinger. Essentials of research design and methodology, John Wiley \& Sons, Inc, New Jersey, 2005. 
[7] L. Cohen, L. Manion, K. Morrison. Research methods in education $\left(6^{\text {th }}\right.$ Ed.), Routledge, London, 2011.

[8] J. Wheeldon. Mapping mixed methods research: methods, measures and meaning, Journal of Mixed Methods Research, Vol.4, No.2, 87-102, 2010.

[9] J. R. Fraenkel, N. E. Wallen. How to design and evaluate research in Education, McGraw-Hill, New York, 2008.

[10] P. E. Slavin. Educational research in an age of accountability, Pearson Education, Inc, New York, 2007.

[11] E. C. Chang. An investigation into the thesis/dissertation writing experiences of Mandarin- speaking Masters students in New Zealand. Unpublished Master's thesis, Lincoln University, Christchurch, 2006.

[12] M. Lowe. Beginning research: A guide for foundation degree students, Routledge, London, 2007.

[13] D. Burton, S. Bartlett. Practitioner research for teachers, Paul Chapman Publishing, London, 2005.

[14] J. A. Holstein, J. F. Gubrium. Handbook of Constructionis Research, Journal of Multidisciplinary Evaluation, Vol. 5, No. $10,93-94,2008$

[15] S. B. Merriam. Qualitative research in practice, Jossey-Bass, San Francisco, 2002.

[16] Compassion Capital Fund Natural Resource Centre (CCFNRC). The working with consultants Guidebook: Strengthening nonprofits, Natural Resources, Washington, D.C, 2010

[17] D. Silverman. Interpreting qualitative data: Methods for analysing talk, text and interaction $\left(3^{\text {rd }} \mathrm{Ed}\right)$, Sage, London, 2006 .

[18] C. J. Marsh, G. Willis. Curriculum: Alternative approaches, ongoing issues $\left(4^{\text {th }}\right.$ ed), Pearson, New Jersey, 2007.

[19] World Bank. Consulting services manual: A comprehensive guide to selection of consultants, The World Bank, Washington, D.C, 2002.

[20] African institute for Mathematical Science - Next Einstein initiative (AIMS-NEI), Curriculum Consultant: Integrated Career Learning at the Masters Level, Online available from http://www.sagea.org.za/ktml2/files/AIMSToRCurriculumCo nsultant.pdf.

[21] R. Barnett. Improving higher education: Total quality care, Open University Press, Buckingham, 1992.
[22] L. J. Harrison, E. M. Golfeld, T. Moore. Closing the gap: Early learning programs that promote children's developmental and educational outcomes. Australian Institute of Health and Welfare, Sidney, 2012

[23] Levine A, Educating school teachers. The education schools project, Online available from http://www.edschools.org/pdf/.

[24] L. Darling-Hammond. The right to learn, Jossey-Bass, San Francisco, 1997.

[25] National Curriculum Development Centre (NCDC). An advert for the senior curriculum specialist-Grade $\mathrm{H}$ for Linguistic and Literacy Learning Area. NCDC-MOET, Maseru, 2010.

[26] World Bank, Guidelines selection and employment of consultants under IBRD loans and IDA credits \& grants by World Bank borrowers, Online available from www.worldbank.org/procure.

[27] Chandler, L. K., Cochran, D. C., Christensen, K. A. Dinnebeil, L. A. Gallagher, P.A., Lifter, K., Stayton, V. D. and Spino, M. (2012). The alignment of CEC/DEC and NAEYC personnel preparation standards. Topics in Early Childhood Special Education, 32 (1) 52-63.

[28] The World Bank, the International Development Association Project Appraisal Document: Mining and Environmental Remediation and Improvement Project, Zambia, 2016.

[29] Lesotho Education Policy. Kingdom of Lesotho: Education sector strategic plan 2005-2015. Government Printing Unit. Maseru, 2005.

[30] Gubrium, J.F. and Holstein, J.A. (2001). Handbook of Interview Research. London: Sage Publishing.

[31] William Pinar (et al., 2014) Understanding Curriculum (Peter Lang Publishers)?

[32] J. Nieuwenhuis. The development of educational systems in post-colonial Africa: A study of a selected number of African countries, HSRC, Pretoria, 1996.

[33] M. Mpeta, L. Nketekete, L. Feiter. Curriculum implementation in Lesotho Schools and school capacity for change in science. Paper presented at SARMSTE Conference, Swaziland, January 11-16th, 2003.

[34] N. K. Monaheng. Implementation tensions and challenges in donor funded curriculum projects: A case analysis of environmental education and population education in Lesotho. Unpublished MED thesis, Rhodes University, Grahamstown, 2007. 